\title{
Has the pandemic impacted non-essential research by medical students?
}

\section{Pandemia impactou pesquisas não essenciais de estudantes de medicina?}

\author{
José Eduardo Nogueira Forni' (1) eduforni@terra.com.br \\ Laura de Souza Lima' \\ Regiane Cristine Campos de Oliveira' ${ }^{1}$ \\ laura.lima@edu.famerp.br \\ regiane.oliveira@edu.famerp.br \\ Fábio Argollo Ferreira' ${ }^{1}$ fabio.argollo@hotmail.com
}

Dear Editor,

The impact of the Covid-19 pandemic on culture, tourism and industry is widely discussed in Brazil. With regards to the health field, patients with diseases or suspected diseases have put off going to the hospital to investigate possible disease or continue treatment. Thus, other serious conditions, such as cancer and malaria, which affect more than 200 million people throughout the world and kill approximately half a million per year ${ }^{1}$, are not being investigated.

This conflict is also apparent in the area of medical research, as $80 \%$ of all biomedical trials that are not related to Covid-19 have been interrupted ${ }^{2}$, along with the closing of laboratories, cancelation of conferences, cuts to funding and researchers suspending their investigations to dedicate their efforts to Covid-19. Studies on the novel coronavirus are considered essential due to the high number of contaminations and deaths, but are studies addressing other diseases also not considered essential ${ }^{3}$ ?

Although the pandemic constitutes an exceptional circumstance in the field of public health, in which all efforts are required to save lives, the return to scientific research not related to Covid-19 is fundamental, as such research can also save lives and improve the quality of life of millions of people affected by serious life-threatening diseases. Financial resources earmarked for studies into Covid-19 could lead to reduced funding for other research projects, as the Brazilian economy has shrunk, as reflected in the country's gross domestic product dropping by $4.1 \%$ in $2020^{4}$.

Undergraduate courses at Brazilian medical schools have also been affected due to the limitation imposed on elective surgical operations and beds on hospital wards and in intensive care units being occupied by Covid-19 patients. This has been detrimental to educational activities involving surgical specialties, which may have repercussions for the qualification of healthcare professionals who will care for patients in the post-Covid-19 era.

Scientific initiation studies in undergraduate courses, which make a substantial contribution to the education of new scientists in the country, have also suffered from the drastic reduction in funding for research and the difficulty in assessing patients, especially in studies that involve investigations of patient quality of life. Due to the fear of contracting the disease at the hospital, difficulties regarding access to the various forms of social communication and a cultural reluctance among patients to complete questionnaires necessary for evaluating results, the scientific initiation projects of undergraduate students at our medical school addressing pain and quality of life in patients following a mastectomy have become unfeasible.

The worries of our future scientists and healthcare professionals, especially in the field of medicine, should be an issue of concern for the government, anticipating negative consequences to the education of scientists and physicians in the post-pandemic era. Efforts should be made to attenuate the harm caused to these students during the two years of social isolation brought by the pandemic, which could lead to an irreparable gap in their education, with serious consequences for society and Brazilian science.

\section{AUTHORS' CONTRIBUTION}

The four authors participated in the conceptualization, planning, methodology and writing of this work.

\footnotetext{
1 Faculdade de Medicina de São José do Rio Preto, São José do Rio Preto, São Paulo, Brazil.
}

Chief Editor: Rosiane Viana Zuza Diniz.

Associate Editor: Daniela Chiesa.

Received on 08/25/21; Accepted on 09/13/21.

Evaluated by double blind review process. 


\section{CONFLICTS OF INTEREST}

The authors declare no conflicts of interest.

\section{SOURCES OF FUNDING}

The authors declare no sources of funding.

\section{REFERENCES}

1. WHO. World Malaria Report. Geneva, Switzerland: World Health Organization. 2019.

2. van Dorn A. COVID-19 and readjusting clinical trials. Lancet. 2020;396(10250):523-4.

3. Yanow SK, Good MF. Nonessential research in the new normal: the impact of COVID-19. Am J Trop Med Hyg. 2020;102(6):1 164-5.

4. Instituto Brasileiro de Geografia e Estatística (IBGE). PIB cai 4,1\% em 2020 e fecha o ano em R\$ 7,4 trilhões. Rio de Janeiro: Agência IBGE. [access in 3 mar 2021]. Available from: https://agenciadenoticias.ibge.gov.br/agenciasala-de-imprensa/2013-agencia-de-noticias/releases/30165-pib-cai-4-1em-2020-e-fecha-o-ano-em-r-7-4-trilhoes. 